\section{Banca al banquillo}

Un juicio abreviado sobre las

condiciones crediticias que

enfrentaron las empresas durante

la última recesión enf-Chile.

por Juan Foxley Rioseco
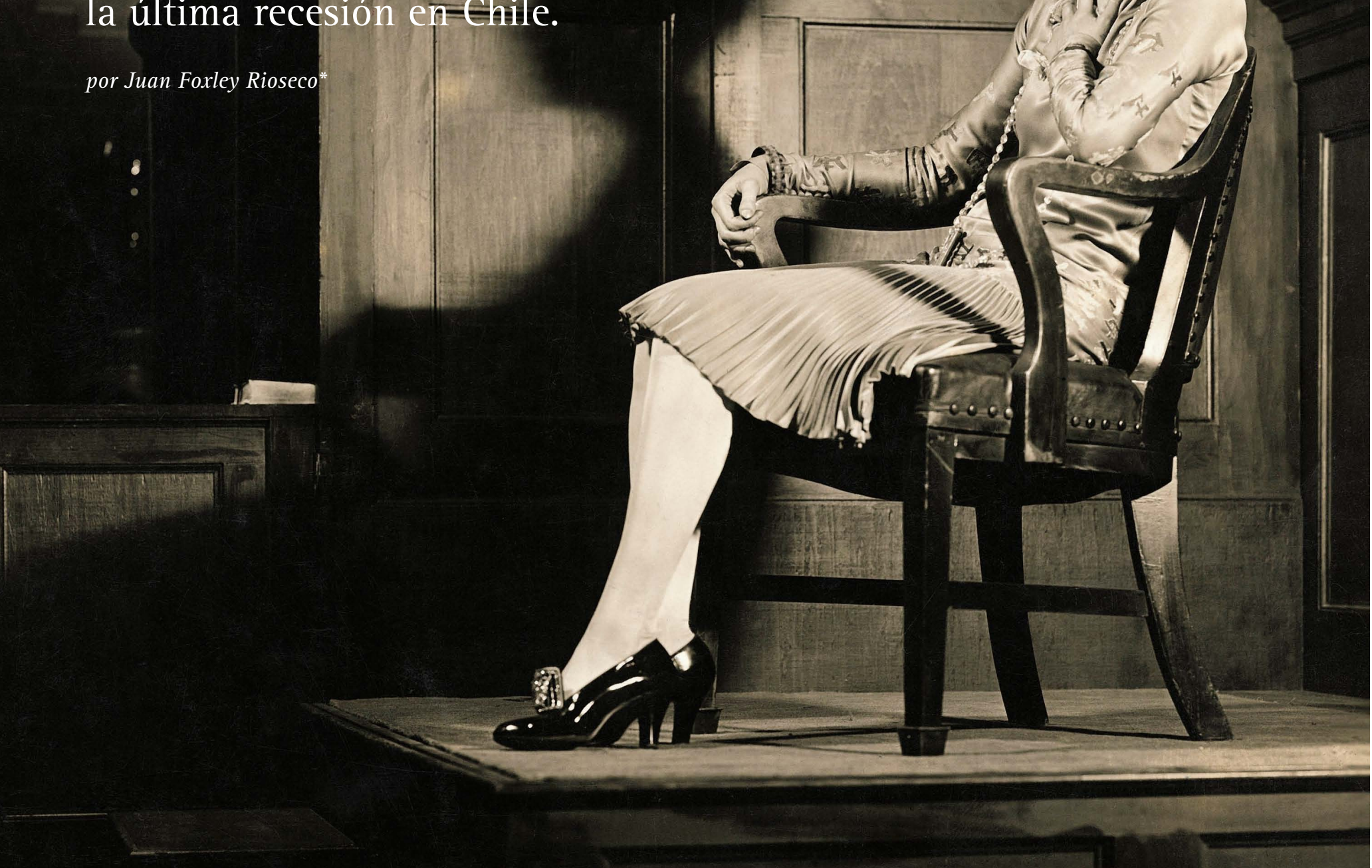

Abundantes han sido las críticas a la banca chilena durante el año. Al reclamo recurrente sobre cargos abusivos, se sumaron ta de créditos y las altas tasas de interés, especialmente en operaciones PYM

Este articulo revisa la información estadistica disponible para créditos comerciales
a la luz de las principales criticas. El intento a la luz de las principales criticas. El intento es enriquecer una discusión donde é oca-
siones, los prejuicios vociferan más que los

siones, los
números.

Shbiera que emitir una sentencia en primera instancia, la evidencia sugiere que un ambiente de insuficiente competencia pero donde el riesgo de insolvencia ha sido bien manejado. A su turno, BancoEstado (BE) ha jugado un rol clave en aumentar competitividad del sistema durante la crisis. Lo hizo si, a costa de exponer su cartera un mayor riesgo, y compensar luego el deterioro con un aporte de capital desde fisco.

Lo enunciado pone en el tapete la disyuntiva esencial que enfrenta cualquier sistema bancario en el mundo: expansión del crédito en un lado y riesgo de insolvencia por el otro.

¿Prestar solo a quienes no lo necesitan? Con toda su ironia, este viejo aforismo de banquero nos recuerda la disyuntiva entre desarrollo económico-social y estabilidad financiera. En la crisis de 1982, los chilenos aprendimos de la peor manera lo caro y toruoso que es terminar pagando las deudas de un lad ni control. Sabemos hace rato, y más excesos de deuda son malos, pero también que niveles de deuda muy bajos pueden dejar proyectos rentables sin explotar.

Con la banca en el banquillo, habria que citar como testigos no solo a los deudores, sino a la Superintendencia de Bancos e Instituciones Financieras (SBIF) y al Banco Central (BC). Ellos son los protectores del bien común y de los depositantes chicos. El riesgo bancario no es solo asunto de accionistas "contra" prestatarios PYME. Lo do un banco quiebra, el peligro no es solo que pierda su capital. Más grave es que sus depositantes pierdan sus ahorros y el pats vea bloqueado su acceso al financiamiento

Esta es precisamente la razón por la que la industria bancaria es un sector regulapor para defender a sus depositantes, especialmente a los más pequeños y menos pormados, y para prevenir "corridas" que pudies paralizar el sistema de pagos. Los linimos de capital más untizados son los . de Basilea" I y III. Cusilo se acusa

Cuando acusa a la banca de cobra correctamente a insuficiente pero rara vez se plantea el trade-off de agregar horas de sueño a los deudores par

¿CRISIS DE CRÉDITO?

En Chile no ha habido credit-crunch. E volumen de préstamos comerciales se ha mantenido estable en moneda nacional: de hecho son hoy algo mayores respecto de semestre precrisis 2008. semestre precrisis 2008. Si se observa (gráfico superior) una baja en los prèstamos en moneda extranjea, dado el corte parcial de lineas de crédito y la caida de exportaciones y de importacong (25\% y $21 \%$, 12 meses a agosto de Laja de colo, respectivamente). tigada por las medidas del BC desde octubre 2008, respecto de ampliar de uno a seis meses las operaciones de swaps en divisas.

ESTÁNDARES DE APROBACIÓN DE PRÉSTAMOS

Aunque a nivel agregado no hubo contraccrediticia en pesos, la situación individual de los deudoresyla demanda de nuevos créditos comerciales se vieron afectadas por el mayor riesgo de repago imperante (gráfico de la derecha).

Los datos de la Encuesta del BC (indices cualitativos sobre la base de un cuestionario realizado a ejecutivos) indican que se hacen más exigentes los estándares de aprobación de créditos, especialmente para las empre-
Colocaciones comerciales

2008-2009 \$Billones* equivalentes

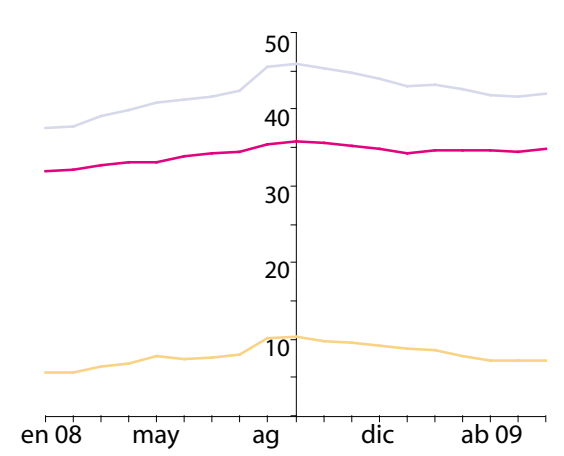

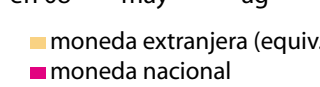

tas

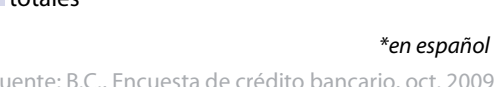

5

Estándares de aprobación de créditos comerciales
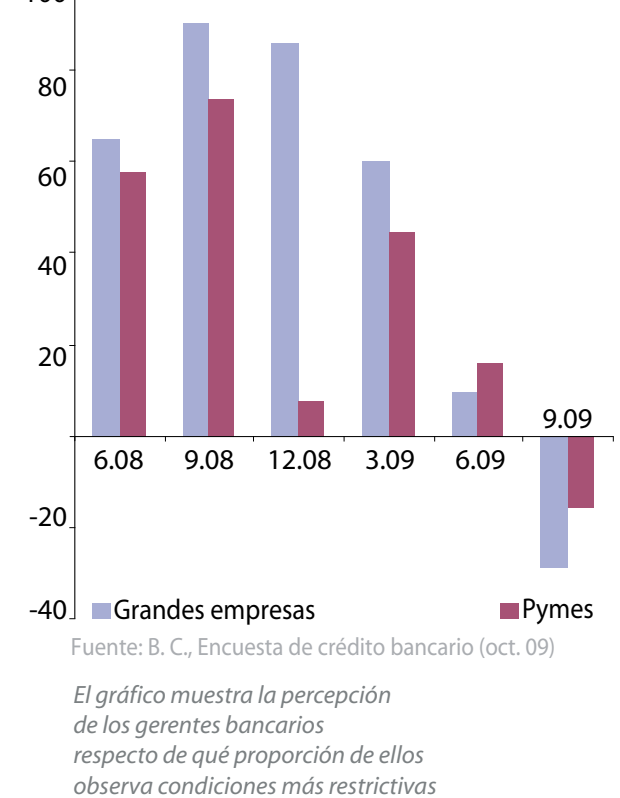

observa condiciones más restrictivas

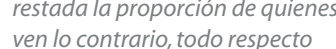


Tasas de interés real promedio y márgenes de intermediación

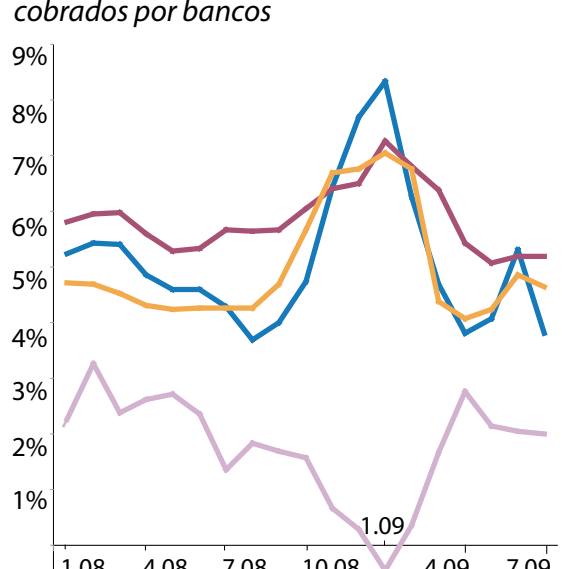

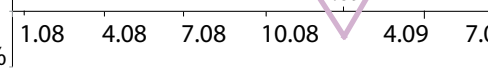

Totales hasta un año Hasta $2000 \mathrm{UEF}$, más de un año
Más de $2000 \mathrm{UF}$, más de un año Spread neto oper. entre 90 dias $y$ un año

Rentabilidad sobre

patrimonio

Sistema

BancoEstado

8.0

6.6

Santander,
de Chile, BCI

$18-23 \quad 18-23$

Fuente: SBIP

*anualizado más pequeñas, son en general evaluadas en anual, según se trate de créditos para comfunción del valor de sus garantías más que pras o avances en efectivo, respectivamente. de sus scores de riesgo crediticio y se ve que No obstante, hay que tener presente que, los estandares de riesgo solo empiezan a re- sea por su riesgo o su costo de operación mase en septiembre 2009. Se aprecia, ade- el credito chico es particularmente caro. Por ae, que las restricciones a las mas grandes ejemplo, el celebre Grameen Bank cobra 22 selajan con un trimestre de anticipacion \% nominal anual promedio a microempreEn el caso de las PYMES (ventas inferiores Crédito Prendario ("Tía Rica"), $34.5 \%$. a UF 100 mil anuales), según la misma encuesta, las mayores restricciones al credito RIESGO, RETORNO Y COMPETENCIA se manifiestan en aumentos de spreads y No hay duda de que la banca ha manejado premios por riesgo más que en el corte de li- bien su riesgo de crédito. Así lo muestra neas de credito o el acortamiento de plazos. aumento de los indices adecuación de capita del 12.1 al $14.1 \%$, en estos úlimos 9 meses. LA BAJA DE TASAS Por otro lado, la rentabilidad en los banA pesar de la mayor discriminación de cos privados varia mucho entre las distindeudores según riesgo y, en particular, el au- tas entidades, pero los altos indices en los de tasas de inteŕs rea cobrad el promedio más grandes sugieren una evidente falta de deudores comercies durante el primer se- concentran poco más de la mitad del patrimestre de 2009 es similar al observado an- monio efectivo y colocaciones del sistema. tes de la crisis (gráfico superior). Lo mismo De otro lado, un quinto de los bancos estaocurre respecto de los spreads netos (már- blecidos en Chile tienen pérdidas y corresgenes de intermediación financiera después ponden en general a entidades con menor de costos del encaje a los depósitos). La opinión pública no advirtió el fuerte centrada principalmente en consumo. descenso de las tasas promedio cobradas a No es factible la liberalización de los partir de 2009. Aparte de los intereses de movimientos de capitales ni menos parece grupo, la causa de tal omisión podría es- prudente pensar en un relajamiento en los tar en la comparación de las tasas pasivas requerimientos de capital minimo para pro(y a un dia) de politica monetaria con las mover mayor competencia. Hoy todos los tasas cobradas a empresas de alto riesgo. reguladores agrupados bajo el G-20 intenRazones de plazo del fondeo y de nuevo, de tan coordinar normativas para exigir mariesgo, hacen impropia dicha comparación. yores provisiones y seguros, especialmente Eso si: las tasas en préstamos de con- a los bancos más grandes². En Chile, la cirsumo, asimilables a ciertas empresas pe- cular 3.476 de la SBIF-próxima a entrar en queñas, se mantienen extraordinariamente vigencia-, establece una desagregación de altas. del orden de $45 \%$ nominal anual en las provisiones por tipo de deudor que, en Ineas de crédito, por ejemplo. Esto refle- la práctica, significará mayor seguridad en jactores de riesgo pero aparentemente, los préstanos sin garantias, pero al mismo Como referencia: las tasas cobradas en tasas de colocación más altas.

Como berencia. las tasas cobradas en tasas de cormo alormativas de disconcentra-

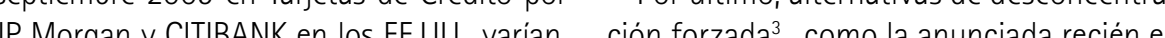
par un buen deudor, entre $9 y 19 \%$ nominat el Reino Unido, solo parecen viables en un sistema en que los bancos más grandes es-

nerables, como las PYMES que dependen de lineas bancarias para capital de trabajo. № los usuarios y la fiscalización de las entioda- obstante, el Estado ha mitigado el riesgo a des para prevenir abusos, debería resaltar- GAPE (hasta $80 \%$ de cobertura).

se como acción clave en el fomento de la El gran desafio es cómo mejorar la compecompetencia. A su turno, el BE parece estar cumpliendo un rol regulador de precios, aunque a costa de su propia solvencia. Mientras los tres privados más grandes otorgaban a agosto de 2009 más del $51 \%$ de los prestamos, su cartera morosa (90 dias o más) alcanzaba solo al 39\% del total impago del sistema. Y aunque solo participaba con el $16.3 \%$ de las co-

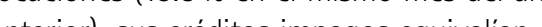
$29 \%$ del total moroso (más que al 21\% de 2008).

BE ha realizado un sacrificio no solo en uti3 puntos de participación de man a cambio cartera era y es peor después de la crisis si se le compara con los tres bancos privados más grandes del sistema. El deterioro fue salvado con un aumento de capital.

\section{EPÍLOGO}

La evolución reciente del crédito comercial no deberia sorprender a quienes han conocido los efectos financieros de otras recesiones en Chile y el mundo. Dado un conjunto de regulaciones prudenciales, mayor riesgo de crédito reinante obliga los bancos a hacer más exigente la aplicación de sus estándares, Castigar cartera constituir mayores provisiones ${ }^{4} y$ defender su solvencia para evitar las perididas propias y el debilitamiento de la fe pública.

Este es un comportamiento beneficioso para la sanidad del sistema financiero renfianza de los depositantes y los costos del endeudamiento externo. Pero significa también inducir un necesario ajuste que tencia entre los bancos sin deteriorar la solvencia del sistema. La actuación y resultados del BE ilustran bien la dificultad de conseguir

test distema bancario está pasando bien solvenci dos bue supone mantener la de los depositantes en y la tranquilidad pero el sistema necen medio de una crisis, competencia

La mejora y estandarización de la inS Jusos son tareas inmediatas que la SBF deberia asumir. Los potenciales deudores epositantes tendrian asi un rol crucial en la vigilancia de la competencia. 'YuNUS, M. Hacia un mundo sin Pobreza. Barcelona,
España : Andrés Bello, 2000. Ver KING, M. Speech, by Mervyn King, Governor of

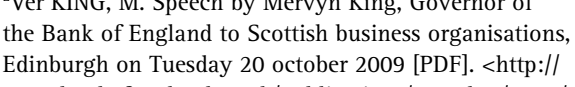
speechno6.pdd (revisado 9 de noviembre 20099.
A. Darling anunció la venta de activos de RBS y Lloyds, mprarian nuevos actores que ayudarian a restaurar
rados de competencia conocidos en el pasado (véase grados de competetencia conocidos en el pasado (véase
Darling Prepares to Unveil Bank Shakeup, The Indepen-

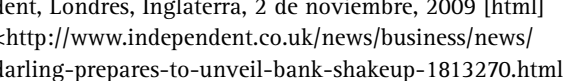

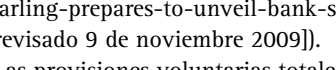
ron entre diciembre de 2008 y agosto de 2009 en 28.720 ron entre diciembre de 2008 y agosto de 2009 en
millones: desde $0.15 \%$ a
ponderados por riesgo. speech406.pdafs [revisado 9 de noviembre 2009].

\section{Oe}

Decano: Jorge Rodríguez Grossi. e-mail: jrodrigu@uahurtado economiaynegocios.uahurtado.cl/observatori Producción OE: Comunicar, Escuela de Periodismo UAH. 